\title{
Facile Protocol for Alkaline Electrolyte Purification and Its Influence on a Ni-Co Oxide Catalyst for the Oxygen Evolution Reaction
}

\author{
Ioannis Spanos, ${ }^{* \dagger}{ }^{\dagger}$ Marc F. Tesch, ${ }^{\dagger}$ Mingquan Yu, Harun Tüysüz, ${ }^{\ddagger}$ Jian Zhang, ${ }^{\S}$ Xinliang Feng, ${ }^{\S}$ \\ Klaus Müllen, ${ }^{\perp \odot}$ Robert Schlögl, ${ }^{\dagger} \|$ and Anna K. Mechler* ${ }^{*} \dagger$ \\ ${ }^{\dagger}$ Department of Heterogeneous Reactions, Max Planck Institute for Chemical Energy Conversion, Stiftstrasse 34-36, 45470 Mülheim \\ an der Ruhr, Germany \\ ${ }^{\ddagger}$ Department of Heterogeneous Catalysis and Sustainable Energy, Max-Planck-Institut für Kohlenforschung, Kaiser Wilhelm-Platz 1, \\ 45470 Mülheim an der Ruhr, Germany \\ ${ }^{\S}$ Department of Chemistry and Food Chemistry, Center for Advancing Electronics, Zellescher Weg 19, 01069 Dresden, Germany \\ "Department of Inorganic Chemistry, Fritz-Haber Institute of the Max Planck Society, Faradayweg 4-6, 14195 Berlin, Germany \\ ${ }^{\perp}$ Department of Synthetic Chemistry, Max Planck Institute for Polymer Research Ackermannweg 10, 55128 Mainz, Germany
}

Supporting Information

ABSTRACT: We report a simple and effective electrochemical method to remove $\mathrm{Fe}$ impurities from commercial $\mathrm{KOH}$ electrolyte. We therefore utilize a $\mathrm{MoS}_{2}$ catalyst deposited on porous $\mathrm{Ni}$ foam as both the anode and cathode in a two-electrode electrolysis setup. After $12 \mathrm{~h}$ of constant galvanostatic electrolysis at $100 \mathrm{~mA}$, the $\mathrm{Fe}$ impurities from the $\mathrm{KOH}$ electrolyte were successfully removed, as confirmed by means of inductively coupled plasma optical emission spectroscopy analysis. In the purified $\mathrm{KOH}$, a $\mathrm{Ni}-\mathrm{Co}_{3} \mathrm{O}_{4}$ composite oxide catalyst showed no $\mathrm{Fe}$-induced activation. In contrast, we directly observed the uptake of $\mathrm{Fe}$ on the $\mathrm{Ni}-\mathrm{Co}_{3} \mathrm{O}_{4}$ catalyst from the nontreated electrolyte during catalyst operation using a coupled spectroelectrochemical setup. Interestingly, we further identified an influence on the dissolution behavior of $\mathrm{Ni}$ and $\mathrm{Co}$ in the presence of Fe impurities. Whereas hitherto mainly the activation effect of $\mathrm{Fe}$ impurities has been discussed, we hereby show that they additionally suppress corrosion under reaction conditions. Using our fast and low-cost method for the purification of large amounts of electrolyte, catalyst materials can be widely studied without these additional effects induced by Fe impurities in commercial $\mathrm{KOH}$.

KEYWORDS: oxygen evolution reaction, electrocatalysis, $\mathrm{Fe}$ impurities, $\mathrm{KOH}$ purification, ICP-OES

$\mathrm{T}$ he fraction of renewable energy has increased over the years to decrease the dependence on fossil-fuel-based energy resources like oil, coal, and so on. To store electrical energy from these more fluctuating sources, chemical energy conversion, for example, by water electrolysis, has been extensively investigated. New and efficient oxide catalyst materials based on Ir and $\mathrm{Ru}$ have been investigated under acidic and alkaline conditions. ${ }^{1-6}$ However, the cost of such materials prohibits their use as catalysts for the oxygen evolution reaction (OER). Thus novel and cheap materials are necessary to replace the expensive and rare precious-metalbased catalysts. It is preferable that such materials should be based on abundant first-row transition metals like $\mathrm{Fe}, \mathrm{Ni}$, and Co. ${ }^{7-14}$ Many studies have been focused on investigating Nibased materials due to their excellent catalytic properties for the OER and on unraveling the mechanism behind the oftenobserved activity enhancement of Ni-based catalysts. $8,11,15-19$ It is well established that $\mathrm{Ni}(\mathrm{OH})_{2} / \mathrm{NiOOH}$ has a beneficial three-dimensionally porous brucite structure that facilitates easy ion transport and charge conductivity, which is ideal for water oxidation in alkaline. It has been proposed that the development of $\mathrm{NiOOH}$ species on the catalyst surface is responsible for the increased OER activity.,14-16 However, doping Ni-based catalysts with metals like Co, Mn, and Fe has shown enhanced catalytic activity due to changes in the electronic structure of the catalyst surface, with the $\mathrm{Ni}-\mathrm{Fe}$ catalysts being the most active in the alkaline environment. It has also been pointed out that $\mathrm{Fe}$ impurities in the $\mathrm{KOH}$ electrolyte, which were formed during industrial production, might be a reason for the activation of $\mathrm{Ni}$-based catalysts if they are incorporated into the catalyst structure. ${ }^{14-16,20}$ The influence of $\mathrm{Fe}$ impurities, inherited in commercial $\mathrm{KOH}$ solution, on the activity and stability of Ni-based catalysts has drawn considerable attention. These previous studies have shown that $\mathrm{Fe}$ impurities, even on the order of ppm, can significantly alter the activity and stability of Ni-based catalysts,

Received: May 10, 2019

Revised: July 5, 2019

Published: August 1, 2019 
especially for thin films. Considering the low $\mathrm{Ni}$ loading in the investigated films (i.e., $100 \mu \mathrm{g} \mathrm{cm}^{-2}$ ), even $\mathrm{Fe}$ impurities in these low concentrations are expected to have a significant impact on the catalyst activity if they are incorporated into the $\mathrm{Ni}$ matrix. Also, to understand the role of $\mathrm{Fe}$ impurities in $\mathrm{Ni}$ based catalysts, control measurements in an Fe-free $\mathrm{KOH}$ solution are critical. A well-established method by Trotochaud et al. ${ }^{14}$ has been extensively used for the purification of $\mathrm{KOH}$ solution from unwanted Fe impurities. However, this method is complicated and costly considering the fact that it requires high-purity chemicals, that is, $\mathrm{Ni}\left(\mathrm{NO}_{3}\right)_{2} \cdot 6 \mathrm{H}_{2} \mathrm{O}$, and only small batches of electrolyte can be purified. On the contrary, here we present a method that can purify large batches of electrolyte, that is, $1 \mathrm{~L}$ or more, in a few hours.

In this work, we report an easy, cheap, and scalable electrochemical method for $\mathrm{KOH}$ electrolyte purification from unwanted Fe impurities with a $\mathrm{MoS}_{2}$ catalyst deposited on a $\mathrm{Ni}$ foam forming $\mathrm{NiS}_{3} / \mathrm{MoS}_{2}$ heterostructures, from now on called $\mathrm{Ni}-\mathrm{MoS}_{2}{ }^{21}$ The above catalyst serves as both an excellent hydrogen evolution reaction (HER) and OER catalyst. Considering the fact that Ni-based catalysts become activated during water electrolysis due to $\mathrm{Fe}$ incorporation, we used $\mathrm{Ni}-$ $\mathrm{MoS}_{2}$ as an active electrocatalyst with a high surface area to remove effectively all $\mathrm{Fe}$ impurities from the electrolyte. The advantage of this method is its applicability to large electrolyte volumes and the avoidance of additional chemical reagents.

The purification of $1 \mathrm{M} \mathrm{KOH}$ (in ultrapure water) was achieved in a two-electrode setup with the $\mathrm{Ni}-\mathrm{MoS}_{2}$ catalyst as both working electrode (WE) and counter electrode (CE) to actively remove $\mathrm{Fe}$ from the solution. Electrolysis at a constant current of $100 \mathrm{~mA}$ was conducted for $12 \mathrm{~h}$ while the solution was continuously circulated with a magnetic stirrer. Liquid samples were regularly extracted and analyzed by inductively coupled plasma optical emission spectroscopy (ICP-OES) to follow the Fe content in the electrolyte (Figure 1) and to exclude the possible addition of other contaminants

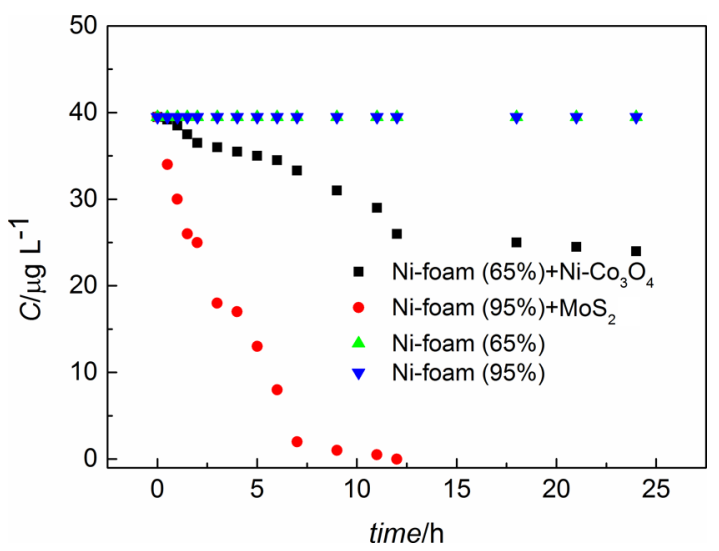

Figure 1. Fe content determination by means of ICP-OES on the $1 \mathrm{M}$ $\mathrm{KOH}$ electrolyte at different intervals of the electrolysis purification procedure.

in the solution from the $\mathrm{Ni}$ foam electrodes, like Ni and Mo. As a comparison, the same purification methodology was used with three additional Ni-foam-based electrodes. Two Ni foams with different porosities (95 and 65\%) used directly as the electrodes for the $\mathrm{KOH}$ purification were unsuccessful in removing $\mathrm{Fe}$ from the electrolyte, even after $25 \mathrm{~h}$ of constant electrolysis. In the case of the $65 \%$ porosity Ni foam, the same
$\mathrm{Ni}-\mathrm{Co}_{3} \mathrm{O}_{4}$ material, also investigated as an OER catalyst in this work, as described later, was deposited on the foam. Although this combined $\mathrm{Ni}$ foam/catalyst electrode was successful to a certain extent in removing almost half of the $\mathrm{Fe}$ content from the electrolyte, the stability issues of this electrode make it unsuitable for prolonged $\mathrm{KOH}$ purification.

On the contrary, with the $\mathrm{MoS}_{2}$ catalyst on the high-porosity (95\%) $\mathrm{Ni}$ foam after $12 \mathrm{~h}$ of electrochemical purification, the initial amount of $\sim 40 \mu \mathrm{g} \mathrm{L}^{-1}$ of Fe was completely removed from the electrolyte up to the detection limit of ICP-OES. No detectable amount of $\mathrm{Fe}$ or other metals was present in the electrolyte, and $\sim 1 \mathrm{~L}$ of $\mathrm{KOH}$ solution was effectively purified. Conveniently, in principle, this procedure can be straightforwardly scaled up by changing the size of the nickel foam and the electrolyte container.

To prove the presence of $\mathrm{Fe}$ on the catalyst, a $\mathrm{Ni}-\mathrm{MoS}_{2}$ foam used for five purifications of each $1 \mathrm{~L}$ of $\mathrm{KOH}$ solution was dissolved in aqua regia, followed by dilution in water at a ratio of $1 / 50$. The amount of $\mathrm{Fe}$ on the $\mathrm{Ni}$ foam was measured with ICP-OES and was found to be $\sim 200 \mu \mathrm{g}$, which is the expected amount of Fe removed from $5 \mathrm{~L}$ of $\mathrm{KOH}$ electrolyte. The same procedure was conducted on the two pure $\mathrm{Ni}$ foams where no Fe removal was evident, and, as expected, no Fe could be detected.

Our results indicate the necessity of an additional active phase on a $\mathrm{Ni}$ foam to effectively remove $\mathrm{Fe}$ species from the electrolyte. However, in previous works, pure $\mathrm{Ni}$ foam was used to remove $\mathrm{Fe}$ impurities from a $\mathrm{KOH}$ electrolyte containing up to $1 \mathrm{ppm}$ of $\mathrm{Fe}$ within 5 days of treatment. ${ }^{22}$ The higher concentration of $\mathrm{Fe}$ and the long experimental time, which eventually leads to an activation of $\mathrm{Ni}$ by forming active surface species, might be the reason for the differences in the results. Nevertheless, we do not exclude that minor amounts of $\mathrm{Fe}$ can be removed by pure $\mathrm{Ni}$ foams even after a $24 \mathrm{~h}$ purification test, but those must be close to or below the detection limit of the ICP-OES. Therefore, if Fe removal indeed occurs on pure $\mathrm{Ni}$, then it must be very slow under the given conditions. As a consequence, the formed $\mathrm{Ni}-\mathrm{MoS}_{2}$ phase can be identified as the active site for Fe removal. This is supported by the fact that $\mathrm{NiS}_{3}$ materials show excellent HER and OER catalytic activity, with further catalytic gains when $\mathrm{Fe}$ is incorporated in the catalyst, ${ }^{23-26}$ which is possibly also the case for $\mathrm{Ni}-\mathrm{MoS}_{2}$.

To elucidate this hypothesis, scanning electron microscopy (SEM) in combination with electron-dispersive X-ray spectroscopy (EDX) elemental mapping is shown in Figure 2.

Sulfur is located preferentially in the vicinity of molybdenium, supporting the presence of $\mathrm{Ni}-\mathrm{MoS}_{x}$ species. Figure $2 \mathrm{~d}$ furthermore shows a strong intensity of $\mathrm{Fe}$ signal close to Mo and $S$, indicating that Fe seems to preferentially deposit on these sites, although some signal can also be detected on the overall $\mathrm{Ni}$ foam. This observation supports the role of the $\mathrm{Ni}-$ $\mathrm{MoS}_{2}$ species as active centers for the Fe removal from the electrolyte.

To test our purification method, we utilized the parallel analysis of catalyst corrosion and activity evaluation during an electrochemical benchmarking protocol on a $\mathrm{Ni}-\mathrm{Co}_{3} \mathrm{O}_{4}$ composite catalyst. Our protocol is designed to test materials for their potential as efficient OER catalysts. ${ }^{27}$

The nanostructured nickel cobalt oxide catalyst used in this work has been prepared through a nanocasting approach using spent tea leaves as a sustainable template. (See Figure S1 for the catalyst characterization and description. $)^{11} \mathrm{~A}$ nickel to 


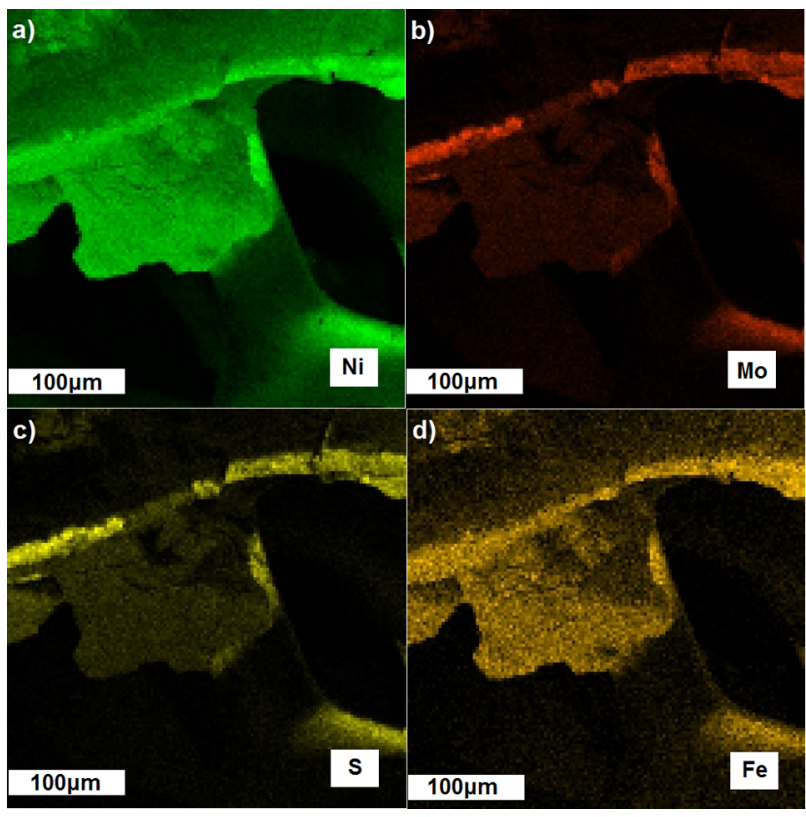

Figure 2. SEM/EDX-derived elemental mapping of a used $\mathrm{Ni}-\mathrm{MoS}_{2}$ catalyst with (a) Ni, (b) Mo, (c) S, and (d) Fe.

cobalt ratio of 1:4 was chosen, which has been reported to be the optimized composition for OER. Following a procedure detailed elsewhere, ${ }^{28,29}$ conditioning of the $\mathrm{Ni}-\mathrm{Co}_{3} \mathrm{O}_{4}$ composite was performed by applying 100 potential cycles between 0.7 and $1.6 \mathrm{~V}_{\mathrm{RHE}}$ at a scan rate of $50 \mathrm{mV} \mathrm{s}^{-1}$. Catalyst conditioning was followed by linear sweep voltammetry (LSV) to determine the activity of the catalyst, defined in this work as the maximum current density at $1.7 \mathrm{~V}_{\mathrm{RHE}}$ after LSV between 1.2 and $1.7 \mathrm{~V}_{\mathrm{RHE}}$ at a scan rate of $5 \mathrm{mV} \mathrm{s}^{-1}$.

By combining electrochemical flow cell (EFC) measurements with online ICP-OES corrosion investigations, we were able to perform quantitative transient analysis of the catalyst corrosion products, like dissolved metal species of $\mathrm{Co}$ and $\mathrm{Ni}$, and additionally for the first time, to the best of our knowledge, follow the $\mathrm{Fe}$ concentration of the $\mathrm{KOH}$ electrolyte during electrochemical testing. Thereby we can in situ investigate the Fe incorporation on the $\mathrm{Ni}-\mathrm{Co}_{3} \mathrm{O}_{4}$ composite catalyst during a typical catalyst stress test. The $\mathrm{Ni}-\mathrm{Co}_{3} \mathrm{O}_{4}$ catalyst corrosion behavior and $\mathrm{Fe}$ concentration in the electrolyte were investigated during a $2 \mathrm{~h}$ chronopotentiometric (CP) stress test at $10 \mathrm{~mA} \mathrm{~cm}$.

Figure 3 compares the stability, corrosion behavior, and $\mathrm{Fe}$ concentration changes in both Fe-contaminated and Fe-free $\mathrm{KOH}$. Whereas with $\mathrm{Fe}$ in the electrolyte the potential initially drops, indicating catalyst activation, and thereafter remains stable over $2 \mathrm{~h}$, it is initially higher in Fe-free $\mathrm{KOH}$ and continuously increases (Figure 3a). This already indicates a deactivation of the catalyst in the absence of $\mathrm{Fe}$ impurities, which is also reflected in the dissolution behavior (as explained later).

To prove the effect of $\mathrm{Fe}$ on the catalyst properties, the concentration of $\mathrm{Fe}$ in the electrolyte was monitored simultaneously along with the corrosion of $\mathrm{Ni}$ and Co during the $2 \mathrm{~h}$ stress test. The concentration of $\mathrm{Fe}$ found in the $\mathrm{KOH}$ electrolyte prior to the start of the stress test was $40 \mu \mathrm{g} \mathrm{L} \mathrm{L}^{-1}$. With the start of the experiment, namely, applying a potential at $t=5 \mathrm{~min}$ (see the Experimental Section for details), an almost immediate drop of the Fe content of the $\mathrm{KOH}$ solution
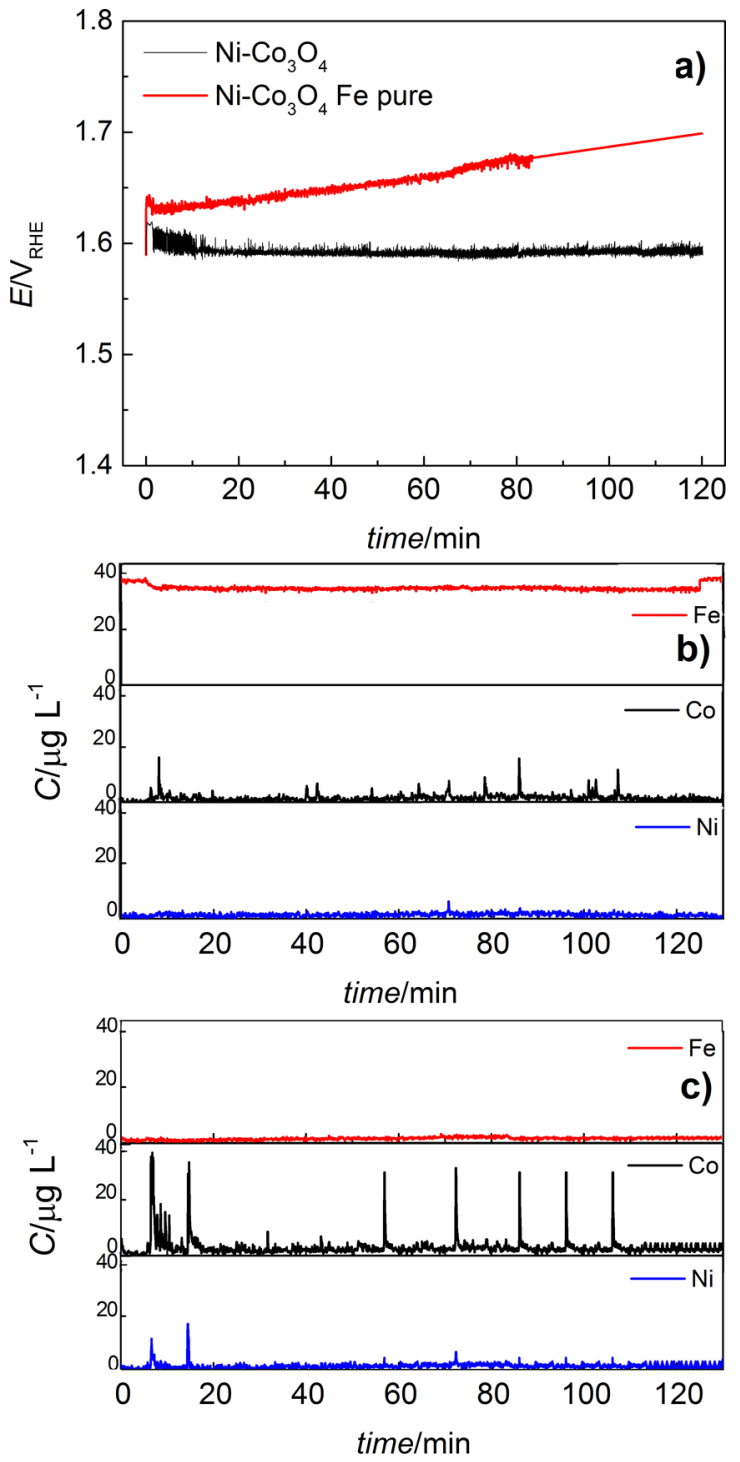

Figure 3. (a) Chronopotentiometry stress test profiles of the $\mathrm{Ni}-$ $\mathrm{Co}_{3} \mathrm{O}_{4}$ catalyst with and without $\mathrm{Fe}$ in solution at $10 \mathrm{~mA} \mathrm{~cm}{ }^{-2}$ for $2 \mathrm{~h}$. ICP-OES transient analysis of the corrosion products of the $\mathrm{Ni}-$ $\mathrm{Co}_{3} \mathrm{O}_{4}$ catalyst in (b) $1 \mathrm{M} \mathrm{KOH} \mathrm{Fe-contaminated} \mathrm{and} \mathrm{(c)} \mathrm{Fe-free}$ $\mathrm{KOH}$ solution. The $\mathrm{Fe}$ content of the $\mathrm{KOH}$ solution was monitored.

was observed (Figure 3b). The loss of Fe from the electrolyte suggests that a certain amount of Fe is incorporated on or into the catalyst surface. In contrast and as expected, in Fe-free $\mathrm{KOH}$ electrolyte, no Fe was detected in the solution (Figure $3 c)$.

Interestingly, the dissolution of the $\mathrm{Ni}-\mathrm{Co}_{3} \mathrm{O}_{4}$ sample in Fefree electrolyte is also significantly affected. In the ICP-OES profiles, corrosion can be seen as signal spikes. Those spikes at different intervals of the ICP-OES profile signify material removal, which could, for example, be due to the accumulation of oxygen gas on the catalyst surface, accelerating material corrosion or catalyst detachment.

However, this gas accumulation must be small because the potential profiles of the catalyst in both electrolytes are smooth with no significant potential spikes (Figure $3 a$ ), which would otherwise indicate bubble formation on the catalyst surface. In the $\mathrm{Fe}$-containing electrolyte, some small signals are visible for $\mathrm{Co}$, indicating minimal Co corrosion, whereas $\mathrm{Ni}$ corrosion could not be detected (Figure 3b). However, in Fe-free $\mathrm{KOH}$, 
significantly more intense spikes in the Co signal occur, and even $\mathrm{Ni}$ initially dissolves (Figure $3 \mathrm{c}$ ). This shows that the incorporation of $\mathrm{Fe}$ on or into the $\mathrm{Ni}-\mathrm{Co}_{3} \mathrm{O}_{4}$ catalyst not only changes the intrinsic activity but also critically influences the corrosion of $\mathrm{Ni}$ and $\mathrm{Co}$ from the catalyst. Even though in both electrolytes catalyst corrosion can be observed, in the case of Fe-free $\mathrm{KOH}$, corrosion is significantly enhanced. This difference in corrosion rates probably affects the deactivation of the catalyst and explains the potential increase in Fe-free $\mathrm{KOH}$.

As a comparison, the same experiment was conducted in 1 $\mathrm{M} \mathrm{KOH}$ purified by the previously reported chemical method. ${ }^{14}$ The $\mathrm{Ni}-\mathrm{Co}_{3} \mathrm{O}_{4}$ catalyst showed exactly the same behavior regarding the activity, stability, and corrosion. (See Figures S2 and S3.) This confirms the good quality of the Fepurified $\mathrm{KOH}$ produced by our simplified electrochemical method.

Besides the effect on the corrosion behavior during an electrochemical stress test, also the impact of the Fe impurities on the activity of the $\mathrm{Ni}-\mathrm{Co}_{3} \mathrm{O}_{4}$ composite OER catalyst were investigated. Figure 4 shows the LSV curves of the $\mathrm{Ni}-\mathrm{Co}_{3} \mathrm{O}_{4}$

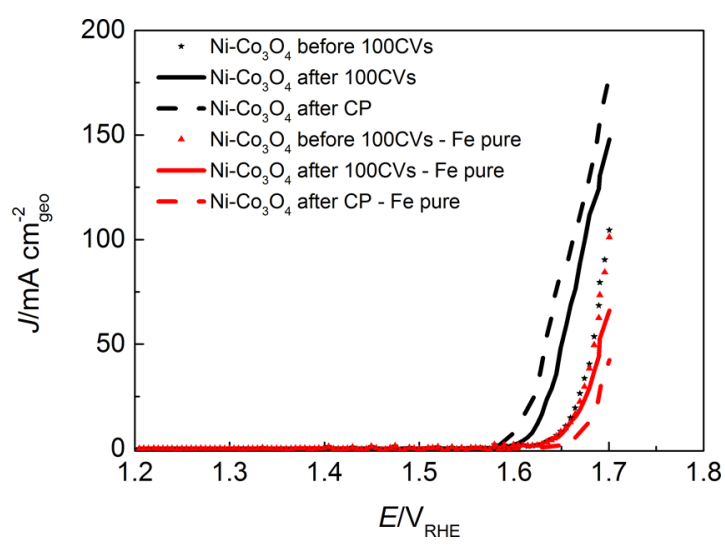

Figure 4. Activity comparison of the $\mathrm{Ni}-\mathrm{Co}_{3} \mathrm{O}_{4}$ catalyst between 1.2 and $1.7 \mathrm{~V}_{\mathrm{RHE}}$ at the $5 \mathrm{mV} \mathrm{s}^{-1}$ scan rate in Fe-contaminated (black) and Fe-pure (red) $1 \mathrm{M} \mathrm{KOH}$.

composite before and after the $100 \mathrm{CV}$ cycles of conditioning as well as after the $2 \mathrm{~h}$ stress test in both standard and Fe-free $\mathrm{KOH}$. As expected, both curves of initial activity, before the $100 \mathrm{CV}$ cycles, are only marginally different, which is expected due to the lack of any $\mathrm{Fe}$ incorporation on the $\mathrm{Ni}-\mathrm{Co}_{3} \mathrm{O}_{4}$ catalyst. After the electrochemical treatment, the curves strongly deviate. In Fe-contaminated $\mathrm{KOH}$, the catalyst is significantly activated after conditioning and even further activated after the $2 \mathrm{~h}$ CP stress test. In total, an almost twofold activity increase can be observed, with a maximum current density increasing from $104 \mathrm{~mA} \mathrm{~cm}^{-2}$ at $1.7 \mathrm{~V}_{\mathrm{RHE}}$ before the $100 \mathrm{CV}$ cycles activation to $178 \mathrm{~mA} \mathrm{~cm}^{-2}$ after the chronopotentiometry stress test. In contrast, an overall activity drop is observed in the Fe-free $\mathrm{KOH}$ solution after both the conditioning and the $2 \mathrm{~h}$ stress test.

Comparing the activity at $1.7 \mathrm{~V}_{\mathrm{RHE}}$ of the $\mathrm{Ni}-\mathrm{Co}_{3} \mathrm{O}_{4}$ catalyst after the $100 \mathrm{CV}$ cycles conditioning between the $\mathrm{Fe}$ contaminated and $\mathrm{Fe}$-free $\mathrm{KOH}$ solutions, there is almost a $20 \%$ difference. This activity difference can be explained by some $\mathrm{Fe}$ incorporation already taking place during the conditioning step. After the $2 \mathrm{~h}$ stress test, this difference is further increased, indicating the severe influence of the $\mathrm{Fe}$ impurities on the catalytic activity of the $\mathrm{Ni}-\mathrm{Co}_{3} \mathrm{O}_{4}$ catalyst during prolonged electrolysis.

Finally, to confirm the incorporation of $\mathrm{Fe}$ on the $\mathrm{Ni}-$ $\mathrm{Co}_{3} \mathrm{O}_{4}$ catalyst, the remaining catalyst was removed from the surface of the gold support after the $2 \mathrm{~h}$ stress test and was dissolved in concentrated $\mathrm{HCl}$. After dilution, the acid solution was inserted into the ICP-OES for analysis. Because only part of the catalyst can be removed by this method, the amount of $\mathrm{Fe}$ detected on the remaining catalyst does not correspond to the total amount of $\mathrm{Fe}$ incorporated on the total $20 \mu \mathrm{g}$ of catalyst initially deposited onto the support. To normalize the amount of $\mathrm{Fe}$ on the catalyst surface, the total detected amount of metals was scaled to fit the amounts of $\mathrm{Ni}$ and Co in $20 \mu \mathrm{g}$ of pristine catalyst.

With this approach, the normalized $\mathrm{Fe}$ amount adsorbed into the catalyst was calculated to be $\sim 0.5 \mu \mathrm{g}$. As a comparison, the incorporated $\mathrm{Fe}$ was calculated from the decrease in Fe concentration in the $\mathrm{KOH}$ solution during the 2 $\mathrm{h}$ stress test (Figure $3 \mathrm{~b}$ ), which was $0.52 \mu \mathrm{g}$. The similarity of the two methods confirms that the drop in concentration during the $2 \mathrm{~h}$ stress test can be assigned to an incorporation of $\mathrm{Fe}$ on the $\mathrm{Ni}-\mathrm{Co}_{3} \mathrm{O}_{4}$ catalyst.

Considering the pristine atomic ratio of $4: 1$ for $\mathrm{Co} / \mathrm{Ni}$, calculated by ICP-OES measurements of a catalyst sample and the amount of incorporated Fe to be $0.52 \mu \mathrm{g}$, this corresponds to one $\mathrm{Fe}$ atom on every ten $\mathrm{Ni}$ atoms, which is reasonable considering the low amount of Fe contained in the electrolyte and, as a result, the even smaller amount incorporated.

To further prove the removal of Fe from $\mathrm{KOH}$ solution with our method, a second sample consisting of a mixture of $\mathrm{NiO}$ and $\mathrm{CoO}$ was tested.

The electrochemical and ICP-OES measurements showed similar behavior to that of the $\mathrm{Ni}-\mathrm{Co}_{3} \mathrm{O}_{4}$ sample, that is, stable performance in $\mathrm{Fe}$-containing $\mathrm{KOH}$ and deactivation in $\mathrm{Fe}$-free $\mathrm{KOH}$. For this second sample, additional soft X-ray absorption spectroscopy at the $\mathrm{Fe}_{3}$ edge in total electron yield mode was performed. For it, the catalyst was measured in its pristine form and after electrochemical measurements in Fe-containing and $\mathrm{Fe}$-free $\mathrm{KOH}$ solution, respectively. Although these measurements do not allow the quantification of the incorporated $\mathrm{Fe}$ on the catalyst, they are very surface-sensitive and therefore ideal to detect even small amounts of $\mathrm{Fe}$ on the surface of the catalyst. Indeed, a clear $\mathrm{Fe}$ absorption feature reveals the presence of $\mathrm{Fe}$ for the sample that was treated in the $\mathrm{Fe}$ containing $\mathrm{KOH}$ solution (Figure S4). Importantly, no Fe was detected in the pristine form of the catalyst and after electrochemical treatment in Fe-free $\mathrm{KOH}$ solution, further corroborating the quality of purification by our approach.

In this work, we have demonstrated a simple electrochemical purification technique with the use of a $\mathrm{Ni}-\mathrm{MoS}_{2}$ catalyst deposited on a $\mathrm{Ni}$ foam, thus making Fe-free $\mathrm{KOH}$ easily available for widespread applications. Whereas a pure $\mathrm{Ni}$ foam was ineffective for $\mathrm{Fe}$ removal, $\mathrm{Ni}-\mathrm{MoS}_{2}$ proved to be the active species that efficiently captures $\mathrm{Fe}$ from the electrolyte. In situ ICP-OES analysis could, for the first time, monitor the uptake of $\mathrm{Fe}$ from the solution during the electrochemical testing of a $\mathrm{Ni}-\mathrm{Co}_{3} \mathrm{O}_{4}$ OER catalyst. Additionally, a significantly higher $\mathrm{Ni}$ and $\mathrm{Co}$ corrosion was detected in $\mathrm{Fe}$ free $\mathrm{KOH}$ compared with the Fe-contaminated $\mathrm{KOH}$, signifying the effect of Fe not only on activating the catalyst but also on preventing its degradation. This proves the high impact of even minimal impurities, as in this case of $\mathrm{Fe}$, on the proper analysis of electrocatalysts for energy conversion and 
the necessity to review former and future publications with regard to the possible activation and stabilization of Ni-based catalysts during OER by Fe incorporation.

\section{EXPERIMENTAL SECTION}

The electrolyte purification was performed electrochemically in a two-electrode setup with a $\mathrm{NiS}_{3}-\mathrm{MoS}_{2}$ catalyst deposited on $\mathrm{Ni}$ foam electrodes of $3 \times 1 \mathrm{~cm}^{2}$ geometric surface area with a high porosity of $95 \%$ (Goodfellow). The molar content of the $\mathrm{MoS}_{2}$ catalyst on the $\mathrm{Ni}$ foam was $8 \%{ }^{21}$ During the electrolysis, a constant current of $100 \mathrm{~mA}$ was applied in a 1 $\mathrm{L}$ standard polystyrene bottle. For a period of $12 \mathrm{~h}$, samples were collected and analyzed with ICP-OES to detect the residual $\mathrm{Fe}$ content. The voltage supplied by the potentiostat was $\sim 1.9 \mathrm{~V}$, with a constant decrease over the $12 \mathrm{~h}$ of electrochemical purification, indicating an activation of the $\mathrm{Ni}$ foam catalyst and signaling the $\mathrm{Fe}$ removal from the $\mathrm{KOH}$ electrolyte and the incorporation on the $\mathrm{Ni}$ foam electrode. Finally, the electrolyte was filtered and stored for further use, whereas the $\mathrm{Ni}$ foam electrodes were thoroughly washed with deionized water and dried under a stream of argon for several minutes. We found that they can be reused several times for purification.

All electrochemical measurements on the $\mathrm{Ni}-\mathrm{Co}_{3} \mathrm{O}_{4}$ catalyst were performed in $1 \mathrm{M} \mathrm{KOH}$ (Fluka Honeywell) with internal resistance (IR) correction. A coil-shaped platinized platinum wire (PT-5W, $125 \mu \mathrm{m}$ diameter, 99.99\%, Science Products), placed along the flow channel following the electrolyte flow, was used as the $\mathrm{CE}$, whereas the reference electrode (RE) $(\mathrm{Hg} / \mathrm{HgO}, \mathrm{CH}$ Instruments, $\mathrm{CHI} 152$, reference potential $+0.098 \mathrm{~V}$ vs NHE) was inserted perpendicular to the electrolyte outlet channel. All potentials are expressed versus the reversible hydrogen electrode (RHE) potential scale. To exclude Pt corrosion and redeposition on the WE during the electrochemical testing, which could affect data evaluation, the same experiment was performed with a glassy carbon $\mathrm{CE}$ (Figure S5), giving similar results. The potentiostat used for the electrochemical measurements was a Bio-Logic SP-150 apparatus, and the embedded EC-Lab software was used to electrochemically monitor the catalysts. Catalysts were dropcasted on gold support measuring a surface area of $0.196 \mathrm{~cm}^{2}$, previously polished with fine 0.05 and $1.0 \mu \mathrm{m}$ alumina powder and ultrasonicated for $15 \mathrm{~min}$ in Milli-Q water. Catalyst inks were prepared by mixing $49 \% \mathrm{H}_{2} \mathrm{O}, 49 \%$ ethanol, and $2 \%$ Nafion solution ( $5 \mathrm{wt} \%$ ) and exposed to ultrasonication for $30 \mathrm{~min}$. Subsequently, a certain amount of catalyst ink was dropcasted on the glassy carbon WE to achieve a loading of $100 \mu \mathrm{g} \mathrm{cm}^{-2}$. The catalyst ink was dried on the gold support under an argon stream for $30 \mathrm{~min}$; finally, the WE sample holder was inserted into the flow cell.

The resulting electrolyte stream was continuously fed into the ICP-OES (Spectroblue EOP, Ametek) by means of a peristaltic pump at a flow rate of $0.86 \mathrm{~mL} \mathrm{~min}^{-1}$ through a quartz nebulizer operating at a nebulizer gas flow rate of $0.85 \mathrm{~L}$ $\mathrm{min}^{-1}$ (Ar, purity 99,999\%). All stability tests in this work were performed in CP mode by applying constant $10 \mathrm{~mA} \mathrm{~cm} \mathrm{~cm}^{-2}$ current density and all current density values were geometric surface area normalized.

For all electrochemical characterization, a flow rate of 0.86

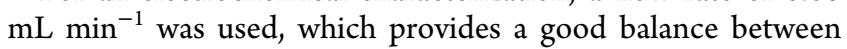
the oxygen gas removal from the catalyst surface and the sufficient detection of the catalyst corrosion products in the ICP-OES. Lower flow rates prohibit reproducible experimental conditions due to excessive oxygen bubble formation at high current densities. Transient signals of $\mathrm{Ni}, \mathrm{Co}$, and $\mathrm{Fe}$ were continuously recorded with an integration interval of $100 \mathrm{~ms}$ and two sweeps per reading, and detection limits were 0.12 $\mathrm{ppb}$ for $\mathrm{Ni}$ and $\mathrm{Co}$ and $0.08 \mathrm{ppb}$ for $\mathrm{Fe}$ according to the manufacturer. For background correction on the ICP-OES data, a 5 min time window before and after the $2 \mathrm{~h} \mathrm{CP}$ analysis, without any current passing through the cell, was used to certify that no signal drift was observed.

Before the measurement, manual calibration was performed using seven standard solutions $(50,10,1,0.5,0.1,0.05$, and 0 ppm metal, prepared from Merck CertiPUR). The plasma power was set to $1400 \mathrm{~W}$ with a plasma gas flow rate of $15 \mathrm{~L}$ $\min ^{-1}$.

For the synthesis of tea-leaf-templated $\mathrm{Ni}-\mathrm{Co}_{3} \mathrm{O}_{4}$, the tea leaves from ceylon pure tea (Goran Mevlana) were utilized as a hard template after a washing treatment with hot water until the washing water became colorless. After drying at $80{ }^{\circ} \mathrm{C}$ under air, $30 \mathrm{~g}$ of tea leaves was added to an aqueous solution (300 mL) containing $12 \mathrm{~g}$ of $\mathrm{Co}\left(\mathrm{NO}_{3}\right)_{2} \cdot 6 \mathrm{H}_{2} \mathrm{O}$ and $3 \mathrm{~g}$ of $\mathrm{Ni}\left(\mathrm{NO}_{3}\right)_{2} \cdot 6 \mathrm{H}_{2} \mathrm{O}$. The stirring was conducted at room temperature for $2 \mathrm{~h}$. After drying at $70{ }^{\circ} \mathrm{C}$ overnight, the obtained mixture was calcined in air at $550{ }^{\circ} \mathrm{C}$ for $4 \mathrm{~h}$ with a ramping rate of $2{ }^{\circ} \mathrm{C} \mathrm{min}{ }^{-1}$. Finally, the product was obtained after being washed with $0.1 \mathrm{M} \mathrm{HCl}$ solution and cleaned with deionized water. $\mathrm{NiO} / \mathrm{CoO}$ was purchased from SigmaAldrich.

The chemical $\mathrm{Fe}$ purification of $\mathrm{KOH}$ solution (as reference) was performed according to the procedure reported by Boettcher's group. ${ }^{14}$ In brief, $2 \mathrm{~g}$ of $99.999 \% \mathrm{Ni}\left(\mathrm{NO}_{3}\right)_{2}$. $6 \mathrm{H}_{2} \mathrm{O}$ was dissolved in $4 \mathrm{~mL}$ of $18.2 \mathrm{M} \Omega \cdot \mathrm{cm} \mathrm{H} \mathrm{H}_{2} \mathrm{O}$ in an acidcleaned polypropylene centrifuge tube, followed by the addition of $20 \mathrm{~mL}$ of $1 \mathrm{M} \mathrm{KOH}$ into the tube to precipitate high-purity $\mathrm{Ni}(\mathrm{OH})_{2}$. Afterward, the mixture was shaken for $30 \mathrm{~min}$ and the supernatant was decanted after centrifugation. The green solid was then washed with $18.2 \mathrm{M} \Omega \cdot \mathrm{cm} \mathrm{H}_{2} \mathrm{O}$ and 1 $\mathrm{M} \mathrm{KOH}$ by redispersing the solid, centrifuging, and decanting the supernatant. $40 \mathrm{~mL}$ of $1 \mathrm{M} \mathrm{KOH}$ solution was added to the tube for purification. In brief, the solid was dispersed in $\mathrm{KOH}$ solution by shaking for $30 \mathrm{~min}$ to purify the Fe from the $\mathrm{KOH}$ solution, followed by $3 \mathrm{~h}$ of rest. The purified $\mathrm{KOH}$ solution was decanted after centrifugation and transferred to an acid polypropylene bottle.

X-ray absorption spectroscopy was carried out at the U49-2 PGM-1 beamline utilizing the LiXEdrom endstation at Helmholtz-Zentrum Berlin.

\section{ASSOCIATED CONTENT}

\section{S Supporting Information}

The Supporting Information is available free of charge on the ACS Publications website at DOI: 10.1021/acscatal.9b01940.

Material characterization by means of SEM, XRD, and BET; supplementary catalyst activity and corrosion behavior in Fe-free electrolyte purified by a different methodology; XAS spectra; and electrochemical characterizations with a GC counter electrode (PDF)

\section{AUTHOR INFORMATION}

\section{Corresponding Authors}

*E-mail: ioannis.spanos@cec.mpg.de (I.S.).

*E-mail: anna.mechler@cec.mpg.de (A.K.M.). 


\section{ORCID $\odot$}

Ioannis Spanos: 0000-0001-5737-4992

Xinliang Feng: 0000-0003-3885-2703

Klaus Müllen: 0000-0001-6630-8786

Anna K. Mechler: 0000-0002-0491-514X

\section{Notes}

The authors declare no competing financial interest.

\section{ACKNOWLEDGMENTS}

This work was supported by the MAXNET Energy consortium of the Max Planck Society. We acknowledge IMPRSRECHARGE. We acknowledge Dr. Xiaohui Deng for his help during the catalyst preparation.

\section{REFERENCES}

(1) Cherevko, S.; Zeradjanin, A. R.; Topalov, A. A.; Kulyk, N.; Katsounaros, I.; Mayrhofer, K. J. J. Dissolution of Noble Metals during Oxygen Evolution in Acidic Media. ChemCatChem 2014, 6, 2219-2223.

(2) Diaz-Morales, O.; Raaijman, S.; Kortlever, R.; Kooyman, P. J.; Wezendonk, T.; Gascon, J.; Fu, W. T.; Koper, M. T. M. Iridium-based double perovskites for efficient water oxidation in acid media. Nat. Commun. 2016, 7, 12363-12368.

(3) Klemm, S. O.; Karschin, A.; Schuppert, A. K.; Topalov, A. A.; Katsounaros, I.; Mayrhofer, K. J. J. Time and potential resolved dissolution analysis of rhodium using a microelectrochemical flow cell coupled to an ICP-MS. J. Electroanal. Chem. 2013, 693, 127.

(4) Schuppert, A. K.; Topalov, A. A.; Katsounaros, I.; Klemm, S. O.; Mayrhofer, K. J. J. A Scanning Flow Cell System for Fully Automated Screening of Electrocatalyst Materials. J. Electrochem. Soc. 2012, 159, F670-F675.

(5) Seitz, L. C.; Dickens, C. F.; Nishio, K.; Hikita, Y.; Montoya, J.; Doyle, A.; Kirk, C.; Vojvodic, A.; Hwang, H. Y.; Norskov, J. K.; Jaramillo, T. F. A highly active and stable $\mathrm{IrO}_{\mathrm{x}} / \mathrm{SrIrO}_{3}$ catalyst for the oxygen evolution reaction. Science 2016, 353, 1011-1014.

(6) Strickler, A. L.; Jackson, A.; Jaramillo, T. F. Active and Stable Ir@Pt Core-Shell Catalysts for Electrochemical Oxygen Reduction. ACS Energy Letters 2017, 2, 244-249.

(7) Burke, M. S.; Enman, L. J.; Batchellor, A. S.; Zou, S.; Boettcher, S. Oxygen Evolution Reaction Electrocatalysis on Transition Metal Oxides and (Oxy)hydroxides: Activity Trends and Design Principles. Chem. Mater. 2015, 27, 7549-7558.

(8) Burke, M. S.; Kast, M. G.; Trotochaud, L.; Smith, A. M.; Boettcher, S. Cobalt-iron (oxy)hydroxide oxygen evolution electrocatalysts: the role of structure and composition on activity, stability, and mechanism. J. Am. Chem. Soc. 2015, 137, 3638-48.

(9) Chen, C.; Kang, Y.; Huo, Z.; Zhu, Z.; Huang, W.; Xin, H. L.; Snyder, J. D.; Li, D.; Herron, J. A.; Mavrikakis, M.; Chi, M.; More, K. L.; Li, Y.; Markovic, N. M.; Somorjai, G. A.; Yang, P.; Stamenkovic, V. R. Highly Crystalline Multimetallic Nanoframes with Three-Dimensional Electrocatalytic Surfaces. Science 2014, 343, 1339.

(10) Deng, X.; Tüysüz, H. Cobalt-Oxide-Based Materials as Water Oxidation Catalyst: Recent Progress and Challenges. ACS Catal. 2014, 4, 3701-3714.

(11) Deng, X. H.; Chan, C. K.; Tüysüz, H. Spent Tea Leaf Templating of Cobalt-Based Mixed Oxide Nanocrystals for Water Oxidation. ACS Appl. Mater. Interfaces 2016, 8, 32488-32495.

(12) Fan, X.; Peng, Z.; Ye, R.; Zhou, H.; Guo, X. M3C (M: Fe, Co, $\mathrm{Ni})$ Nanocrystals Encased in Graphene Nanoribbons: An Active and Stable Bifunctional Electrocatalyst for Oxygen Reduction and Hydrogen Evolution Reactions. ACS Nano 2015, 9, 7407-7418.

(13) Grewe, T.; Deng, X.; Weidenthaler, C.; Schüth, F.; Tüysüz, H. Design of Ordered Mesoporous Composite Materials and Their Electrocatalytic Activities for Water Oxidation. Chem. Mater. 2013, $25,4926-4935$.

(14) Trotochaud, L.; Young, S. L.; Ranney, J. K.; Boettcher, S. Nickel-iron oxyhydroxide oxygen-evolution electrocatalysts: the role of intentional and incidental iron incorporation. J. Am. Chem. Soc. 2014, 136, 6744-53.

(15) Ahn, H. S.; Bard, A. J. Surface Interrogation Scanning Electrochemical Microscopy of $\mathrm{Ni}(1-\mathrm{x}) \mathrm{Fe}(\mathrm{x}) \mathrm{OOH}(0<\mathrm{x}<0.27)$ Oxygen Evolving Catalyst: Kinetics of the "fast" Iron Sites. J. Am. Chem. Soc. 2016, 138, 313-8.

(16) Friebel, D.; Louie, M. W.; Bajdich, M.; Sanwald, K. E.; Cai, Y.; Wise, A. M.; Cheng, M.; Sokaras, D.; Weng, T.; Alonso-Mori, R.; Davis, R. C.; Bargar, J. R.; Norskov, J. K.; Nilsson, A.; Bell, A. T. J. Am. Chem. Soc. 2015, 137, 1305-13.

(17) Ma, T. Y.; Dai, S.; Jaroniec, M.; Qiao, S. Z. Metal-organic framework derived hybrid Co3O4-carbon porous nanowire arrays as reversible oxygen evolution electrodes. J. Am. Chem. Soc. 2014, 136, 13925-31.

(18) McCrory, C. C. L.; Jung, S.; Ferrer, I. M.; Chatman, S. M.; Peters, J. C.; Jaramillo, T. F. Benchmarking hydrogen evolving reaction and oxygen evolving reaction electrocatalysts for solar water splitting devices. J. Am. Chem. Soc. 2015, 137, 4347-57.

(19) Wang, J.; Cui, W.; Liu, Q.; Xing, Z.; Asiri, A. M.; Sun, X. Recent Progress in Cobalt-Based Heterogeneous Catalysts for Electrochemical Water Splitting. Adv. Mater. 2016, 28, 215-30.

(20) Klaus, S.; Cai, Y.; Louie, M. W.; Trotochaud, L.; Bell, A. T. Effects of Fe Electrolyte Impurities on $\mathrm{Ni}(\mathrm{OH}) 2 / \mathrm{NiOOH}$ Structure and Oxygen Evolution Activity. J. Phys. Chem. C 2015, 119, 72437254.

(21) Zhang, J.; Wang, T.; Pohl, D.; Rellinghaus, B.; Dong, R.; Liu, S.; Zhuang, X.; Feng, X. Interface Engineering of $\mathrm{MoS}_{2} / \mathrm{Ni}_{3} \mathrm{~S}_{2}$ Heterostructures for Highly Enhanced Electrochemical OverallWater-Splitting Activity. Angew. Chem. 2016, 128, 6814-6819.

(22) Corrigan, D. A. The Catalysis of the Oxygen Evolution Reaction by Iron Impurities in Thin Film Nickel Oxide Electrodes. J. Electrochem. Soc. 1987, 134, 377-384.

(23) Cheng, N.; Liu, Q.; Asiri, A. M.; Xing, W.; Sun, X.; et al. A Fedoped Ni3S2 particle film as a high-efficiency robust oxygen evolution electrode with very high current density. J. Mater. Chem. A 2015, 3, 23207-23212.

(24) Feng, L.-L.; Yu, G.; Wu, Y.; Li, G.-D.; Li, H.; Sun, Y.; Asefa, T.; Chen, W.; Zou, X. High-Index Faceted Ni3S2 Nanosheet Arrays as Highly Active and Ultrastable Electrocatalysts for Water Splitting. J. Am. Chem. Soc. 2015, 137, 14023-14026.

(25) Sitthikhankaew, R.; Predapitakkun, S.; Kiattikomol, R.; Pumhiran, S.; Assabumrungrat, S.; Laosiripojana, N. Comparative Study of Hydrogen Sulfide Adsorption by using Alkaline Impregnated Activated Carbons for Hot Fuel Gas Purification. Energy Procedia $2011,9,15-24$.

(26) Zou, X.; Sun, Q.; Zhang, Y.; Li, G.-D.; Liu, Y.; Wu, Y.; Yang, L.; Zou, X. Ultrafast surface modification of $\mathrm{Ni}(3) \mathrm{S}(2)$ nanosheet arrays with $\mathrm{Ni}-\mathrm{Mn}$ bimetallic hydroxides for high-performance supercapacitors. Sci. Rep. 2018, 8, 4478-4478.

(27) Spanos, I.; Auer, A. A.; Neugebauer, S.; Deng, X.; Tüysüz, H.; Schlögl, R. Standardized Benchmarking of Water Splitting Catalysts in a Combined Electrochemical Flow Cell/Inductively Coupled Plasma-Optical Emission Spectrometry (ICP-OES) Setup. ACS Catal. 2017, 7, 3768-3778.

(28) Deng, X.; Chen, K.; Tüysüz, H. Protocol for the Nanocasting Method: Preparation of Ordered Mesoporous Metal Oxides. Chem. Mater. 2017, 29, 40-52.

(29) Deng, X.; Öztürk, S.; Weidenthaler, C.; Tüysüz, H. IronInduced Activation of Ordered Mesoporous Nickel Cobalt Oxide Electrocatalyst for the Oxygen Evolution Reaction. ACS Appl. Mater. Interfaces 2017, 9, 21225-21233. 